9. Barrett JC, Fry B, Maller J, et al. Haploview: analysis and visualization of LD and haplotype maps. Bioinformatics 2005;21:263-265.

10. Toth G, Gaspari Z, Jurka J. Microsatellites in different eukaryotic genomes: survey and analysis. Genome Res 2000;10:967-981.

11. Wijnen JT, Morreau H, Vasen HF. [From gene to disease; from DNA 'mismatch' repair genes to hereditary non-polyposis colorectal carcinoma]. Ned Tijdschr Geneeskd 2001;145:780-782.

12. Kovach MJ, Ruiz J, Kimonis K, et al. Genetic heterogeneity in autosomal dominant essential tremor. Genet Med 2001;3:197-199.

13. Illarioshkin SN, Ivanova-Smolenskaya IA, Rahmonov RA, et al. Clinical and genetic study of familial essential tremor in an isolate of Northern Tajikistan. Mov Disord 2000;15:1020-1023.

14. Abbruzzese G, Pigullo S, Di Maria E, et al. Clinical and genetic study of essential tremor in the Italian population. Neurol Sci 2001;22:39-40.

15. Mountain JL, Risch N. Assessing genetic contributions to phenotypic differences among 'racial' and 'ethnic' groups. Nat Genet 2004;36:S48-S53.

\title{
G2019S Dardarin Substitution Is a Common Cause of Parkinson's Disease in a Portuguese Cohort
}

\begin{abstract}
Jose Miguel Bras, MS, ${ }^{1-3}$ Rita Joao Guerreiro, MS, ${ }^{1-3}$ Maria Helena Ribeiro, BS, ${ }^{1,2}$ Cristina Januario, MD, ${ }^{1}$ Ana Morgadinho, MD, ${ }^{1}$

Catarina Resende Oliveira, $\mathrm{MD}, \mathrm{PhD},{ }^{1,2}$

Luis Cunha, MD, PhD, ${ }^{1}$ John Hardy, $\mathrm{PhD},{ }^{3}$ and Andrew Singleton, $\mathrm{PhD}^{3 *}$

${ }^{1}$ Neurology Service, Coimbra University Hospital, Coimbra, Portugal; ${ }^{2}$ Institute of Biochemistry, Faculty of Medicine, Center for Neurosciences and Cell Biology, University of Coimbra, Coimbra, Portugal; ${ }^{3}$ Laboratory of Neurogenetics, National Institutes on Aging, National Institutes of Health, Bethesda, Maryland, USA
\end{abstract}

\begin{abstract}
LRRK2 mutations have recently been described in families with Parkinson's disease. Here we show that one of them $(\mathrm{G2019S})$ is present in $6 \%(7$ of 124) unrelated cases of disease in a clinic-based sample series from central Portugal, but not present in $\mathbf{1 2 6}$ controls from the same population. Thus, LRRK2 mutations appear to be a common cause of typical Parkinson's disease and as such will alter clinical practice. (C) 2005 Movement Disorder Society
\end{abstract}

Key words: $L R R K 2$; dardarin; PARK8; Parkinson's disease

While Parkinson's disease (PD) is conventionally thought of as a sporadic disease and considerable effort

\footnotetext{
*Correspondence to: Dr. Andrew Singleton, Laboratory of Neurogenetics, National Institutes on Aging, NIH, Room A1A, Porter Neuroscience Center, 35 Convent Road, Bethesda, MD 20852.

E-mail: singleta@mail.nih.gov

Received 8 February 2005; Revised 13 April and 19 May 2005; Accepted 27 May 2005

Published online 7 September 2005 in Wiley InterScience (www. interscience.wiley.com). DOI: 10.1002/mds.20682
}

has been expended to find environmental risk factors, over the past 8 years the role of genetic factors has clearly been shown to be of major importance. Mutations in $\alpha$-synuclein have been shown to cause autosomal dominant $\mathrm{PD},{ }^{1}$ and mutations in parkin, $D J-1$, and PINK1 have been shown to cause early-onset Parkinsonism in a recessive fashion. ${ }^{2-4}$ However, all these mutations are comparatively rare and none of them have had a widespread impact on clinical practice. ${ }^{5}$

Recently, mutations in LRRK2, encoding the protein dardarin, were identified as causes for autosomal dominant PD. ${ }^{6,7}$ A series of point mutations has been subsequently described in families with clinical phenotypes ranging from typical Parkinson's disease to very atypical Parkinsonisms. ${ }^{6-13}$ In our screening of families with Parkinson's disease for mutations, two have shown up more than once. These are R1441G (formerly reported as R1396G, ${ }^{6}$ revised codon numbering based on accession number AY792511; all codon and exon numbering here based on AY792511), identified in several Basque patients, ${ }^{6}$ and G2019S, identified in several populations. ${ }^{9-13}$ We determined to test for these two mutations in a series of patients with Parkinson's disease, which we identified in the Movement Disorders Clinic at the Coimbra University Hospital in central Portugal.

\section{PATIENTS AND METHODS}

One hundred twenty-eight cases of clinically typical Parkinson's disease were collected at the Movement Disorders Clinic at the Coimbra University Hospital. This is a consecutive clinic case series comprised of patients who gave permission for sampling. The patients were all Caucasian and of apparent Portuguese ancestry, although a detailed genealogical history outside of the nuclear family was not taken. In this clinic, more than $90 \%$ of cases consent for blood sampling. The control series, which was from the same region, largely consisted of spouses of affected individuals. The criteria for Parkinson's disease diagnosis were the United Kingdom Brain Bank Criteria. ${ }^{14}$ The clinical PD evaluation was done using Unified Parkinson's Disease Rating Scale (UPDRS) and Hoehn and Yahr scale. All the cases were diagnosed with levodopa-responsive Parkinson's disease by a neurologist with experience in PD. A summary of the clinical features of the case series is given in Table 1. All control individuals were examined by a neurologist and were found to be free of any movement disorder or neurodegenerative disease. Mini-Mental State Examination (MMSE) was used as a screening test and no other cognitive test was performed. MMSE scores used for the diagnosis are less than 15 for individuals who never went to school, less than 22 for individuals with 1 to 11 years 
TABLE 1. Clinical features of Portuguese patients studied

\begin{tabular}{lcc}
\hline \multicolumn{1}{c}{ Characteristic } & $\begin{array}{c}\text { Subjects } \\
(\mathrm{n}=128)\end{array}$ & $\begin{array}{c}\text { Mutation carriers } \\
(\mathrm{n}=11)\end{array}$ \\
\hline $\begin{array}{c}\text { Age at collection } \\
\quad(\text { mean } \pm \text { SD) }\end{array}$ & $67.2 \pm 10.3$ & $67 \pm 7.7$ \\
$\begin{array}{l}\text { Age at onset (mean } \\
\quad \pm \text { SD) }\end{array}$ & $57.1 \pm 12.0$ & $54.8 \pm 9.5$ \\
$\begin{array}{l}\text { Range of age at onset } \\
\text { Other features }\end{array}$ & $30-84$ & $38-68$ \\
$\quad \begin{array}{l}\text { Dystonia (non drug } \\
\text { induced) }\end{array}$ & $27(0.21)$ & \\
Dementia & $15(0.15)$ & $5(0.45)$ \\
Essential tremor & $6(0.04)$ & $2(0.18)$ \\
Family history & & $0(0.0)$ \\
$\quad$ Positive & $26(0.20)$ & $6(0.54)$ \\
Negative & $102(0.80)$ & $5(0.45)$ \\
Affected relatives (n) & & \\
1 & $20(0.81)$ & $0(0.0)$ \\
2 & $4(0.15)$ & $2(0.18)$ \\
3 & $1(0.04)$ & $0(0.0)$ \\
+3 & 1 & $0(0.0)$ \\
\hline
\end{tabular}

Values are expressed as $\mathrm{n}$ (frequency), unless otherwise indicated.

of school, and less than 27 for individuals with more than 11 years of school.

\section{DNA Sequencing}

After obtaining informed consent, approved by the Coimbra University Hospital Ethical Committee, a $10 \mathrm{ml}$ blood sample was taken and DNA was extracted by standard procedures. For sequencing, exons 31 and 41 of all the case and control DNA were PCR-amplified from the genomic sample using primers 5'-TCAACAGGAATGTGAGCAGG-3' $/ 5^{\prime}$-CCCACAATTTTAAGTGAGTTGC- $3^{\prime}$ and $5^{\prime}$-TTTTGATGCTTGACATAGTGGAC-3' ${ }^{\prime}$ 5'-CACATCTGAGGTCAGTGGTTATC-3', respectively.

In addition, we sequenced all 51 exons of the gene in 16 of the familial cases using primers previously described for exons $1-5$ and 7-51 and forward primer 5'-GGAAGGGCTGCTTCACAGAAAT $-3^{\prime}$ and reverse primer $5^{\prime}$-GAATGGGTTGAGCATCCACAAG-3' for exon $6 .{ }^{6} \mathrm{In}$ all cases, the products were sequenced using the same forward and reverse primers with Applied Biosystems BigDye terminator and run on an ABI3100 genetic analyzer as per the manufacturer's instructions (Applied Biosystems, Foster City, CA). The sequences were analyzed with Sequencher software (Genecodes, Ann Arbor, MI).

\section{RESULTS}

In our series of 128 consecutive patients, 11 (9\%) had the G2019S mutation; none had the R1441G mutation. The mutations occurred in five sporadic cases of disease and in two families. Discounting the secondary cases in these families, the mutation prevalence in probands is
$7 / 124$ (6\%). In addition, our sequencing of the rest of the gene in a subset of familial disease failed to identify other mutation carriers. The mutation-positive patients presented with an akinetic-rigid syndrome $(\mathrm{n}=5)$ or a tremor-predominant disease $(\mathrm{n}=6)$. In both families with the G2019S mutation, the mutation occurred in all three affected family members who had attended the clinic together. In Family A (Fig. 1), both parents in this kindred were apparently healthy and by history died of nonneurological disease in their 80s. The three individuals are siblings and appear to be the only affected family members. Two of the patients show an akinetic-rigid syndrome while the other presented with resting tremor. Two individuals also had cognitive impairment beginning after their parkinsonian syndrome. Family members A2 and A3 showed cognitive decline (MMSE scores 22 and 13 , respectively). In the second family, two of the mutation carriers (B2 and B3) presented with painful cervical dystonia, which was responsive to levodopa, and neither showed tremor or dementia. In this family, the parents died at ages 69 and 80 without neurological illness according to the family report. For the five sporadic cases, parental mortality information was available for three of them. In two, the father died at less than 55 years and the mother died at 70 years; in the third, both parents died at an age greater than 70. It is worth noting that the case with the youngest age of onset (38 years) is an identical twin, whose twin remains clinically unaffected. Neither of the families and none of the sporadic cases are known to be related to each other, nor did they come from the same villages. Thus, there is no suggestion that these individuals share a recent founder. In
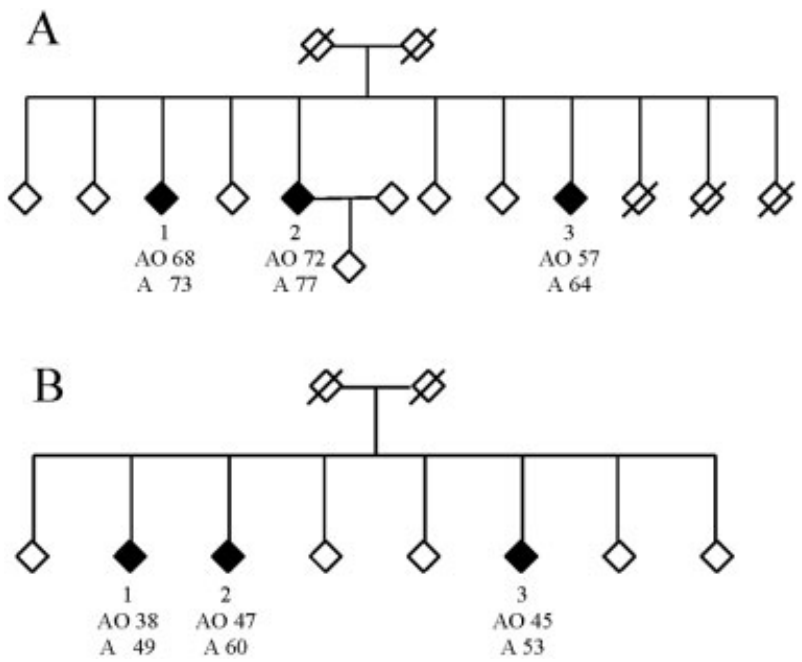

FIG. 1. Families A and B, positive for $L R R K 2$ G2019S mutation. All affected family members are carriers of the mutation. AO, age at onset; A, current age. 
addition, though the ethnic background of the two families from the United States is not known, ${ }^{12}$ there is no hint of Portuguese ancestry; rather, German and Irish are discussed as the likely ethnic backgrounds.

\section{DISCUSSION}

The pathogenicity of the G2019S is clear for three reasons. First, our previous data showed segregation of this mutation in two families from North America. Second, the limited segregation in the two families we have examined also shows segregation of mutation with disease. Third, we did not find this mutation in controls in our control series here, nor have we found this variant in more than 1,500 control subjects from North America (data not shown). ${ }^{9}$

These data are remarkable and of clinical importance for the simple reason that they show that a high proportion of clinically typical Parkinson's disease in this population, as in the Basque population, ${ }^{6}$ carries a pathogenic mutation. Many of these cases do not have familial disease, and, given the information from the two familial cases, the likely reason for this nonpenetrance even at high age in the parents is unclear. These findings will have an impact on clinical practice. Neurologists treating Parkinson's disease have usually assured their patients that the disease was not genetic in etiology and certainly have not routinely suggested genetic testing. These data suggest that this widespread advice and practice will have to change. A large proportion of cases, certainly from Portugal and from the Basque country, carry mutations that put their family members at very high risk for disease, although the likely ages of onset are extremely difficult to predict. This latter fact is underscored by the finding that the identical twin of one of the sporadic mutation carriers remains unaffected 24 years after the onset in his brother, demonstrating that, even in this autosomal dominant disorder, environmental or stochastic factors play an important role in determining the age of onset. Putting these data into clinical practice will entail education of both clinicians and patients and also the inclusion of more genetic counselors in movement disorders practices. On the positive side, the identification of these patients offers the prospect of better and earlier diagnosis and thus of more effective clinical practice.

\section{REFERENCES}

1. Polymeropoulos MH, Lavedan C, Leroy E, et al. Mutation in the alpha-synuclein gene identified in families with Parkinson's disease. Science 1997;276:2045-2047.

2. Kitada T, Asakawa S, Hattori N, et al. Mutations in the parkin gene cause autosomal recessive juvenile Parkinsonism. Nature 1998; 392:605-608.

3. Bonifati V, Rizzu P, van Baren MJ, et al. Mutations in the DJ-1 gene associated with autosomal recessive early-onset Parkinsonism. Science 2003;299:256-259.

4. Valente EM, Abou-Sleiman PM, Caputo V, et al. Hereditary earlyonset Parkinson's disease caused by mutations in PINK1. Science 2004;304:1158-1160.

5. McInerney-Leo A, Hadley DW, Gwinn-Hardy K, Hardy J. Genetic testing in Parkinson's disease. Mov Disord 2005;20:1-10.

6. Paisan-Ruiz C, Jain S, Evans EW, et al. Cloning of the gene containing mutations that cause PARK8-linked Parkinson's disease. Neuron 2004;44:595-600.

7. Zimprich A, Biskup S, Leitner P, et al. Mutations in LRRK2 cause autosomal-dominant Parkinsonism with pleomorphic pathology. Neuron 2004;44:601.

8. Funayama M, Hasegawa K, Kowa H, Saito M, Tsuji S, Obata F. A new locus for Parkinson's disease (PARK8) maps to chromosome 12p11.2-q13.1. Ann Neurol 2002;51:296-301.

9. Nichols WC, Pankratz N, Hernandez D, et al. Genetic screening for a single common $L R R K 2$ mutation in familial Parkinson's disease. Lancet 2005;365:410-412.

10. Gilks WP, Abou-Sleiman PM, Gandhi S, et al. A common LRRK2 mutation in idiopathic Parkinson's disease. Lancet 2005;365:415416.

11. Di Fonzo A, Rohe CF, Ferreira J, et al. A frequent $L R R K 2$ gene mutation associated with autosomal dominant Parkinson's disease. Lancet 2005;365:412-415.

12. Hernandez DG, Paisán-Ruiz C, McInerney-Leo A, et al. Clinical and PET evaluation of Parkinson disease caused by a LRRK2 mutation. Ann Neurol 2005;57:453-456.

13. Kachergus J, Mata IF, Hulihan M, et al. Identification of a novel LRRK2 mutation linked to autosomal dominant Parkinsonism: evidence of a common founder across European populations. Am J Hum Genet 2005;76:672-680.

14. Hughes AJ, Daniel SE, Lees AJ. Improved accuracy of clinical diagnosis of Lewy body Parkinson's disease. Neurology 2001;57: 1497-1499. 